\title{
PELATIHAN SOLUSI PEMULIHAN EKONOMI BERBASIS TEKNOLOGI GEOSPASIAL UNTUK PEMERINTAH DAERAH
}

\author{
Handoko Dwi Julian1) \\ ${ }^{1)}$ Program Studi Survei dan Pemetaan, Fakultas Teknik, Universitas Indo Global Mandiri, Palembang, Sumatera Selatan, \\ Indonesia \\ Corresponding author : Handoko Dwi Julian \\ E-mail : handokodwijulian@uigm.ac.id
}

Diterima 02 November 2021, Direvisi 26 November 2021, Disetujui 26 November 2021

\begin{abstract}
ABSTRAK
Pemahaman mengenai teknologi geospasial sangatlah penting khususnya bagi OPD (Organisasi Perangkat Daerah) untuk meningkatkan kompetensi sumber daya manusia di masing-masing Instansi terkait. Pelatihan mengenai pengaplikasian data digital menggunakan web ArcGIS Online menjadi salah satu alternatif untuk meningkatkan pengetahuan mengenai teknologi geospasial. Sasaran mitra penyampaian materi ini adalah OPD (Organisasi Perangkat Daerah) di Provinsi Sumatera Selatan. Pelatihan dilaksanakan dengan metode jarak jauh menggunakan platform rapat virtual. Peserta pelatihan diberikan modul dan dipandu tahapan demi tahapan dalam selama proses pelatihan berlangsung. Luaran dari pelatihan ini menunjukkan adanya peningkatan signifikan pada para peserta mengenai pemahaman teknologi spasial baik secara teoritis dan praktis. Hal tersebut berdampak baik bagi instansi-instansi khususnya untuk menyelesaikan segala permasalahan terkait geospasial.
\end{abstract}

Kata kunci: teknologi; geospasial; data; digital.

\begin{abstract}
An understanding of geospatial technology is very important, especially for OPD (Regional Apparatus Organizations) to improve the competence of human resources in each related institution. Training on the application of digital data using the ArcGIS Online web is an alternative to increase knowledge about geospatial technology. The target partners for this material delivery are OPD (Regional Apparatus Organizations) in South Sumatra Province. The training is conducted remotely using a virtual meeting platform. Training participants are given modules and guided step by step during the training process. The output of this training showed a significant improvement in the participants' understanding of spatial technology both theoretically and practically. This has a good impact on agencies in particular to solve all problems related to geospatial.
\end{abstract}

Keywords: technology; geospatial; data.

\section{PENDAHULUAN}

Menurut Prahasta (2009) Sistem Informasi Geografis merupakan perangkat lunak yang memiliki fungsi sebagai input, penyimpanan, manipulasi, menampilkan suatu data berbasis informasi geografis beserta atributnya. Terdapat beberapa gabungan pada Sistem Informasi Geografis antara lain sistem, informasi, dan geografis (Budiyanto, 2010). Sistem Informasi Geografis generasi pertama merupakan ArcGIS Desktop yang kemudian terus berkembang menjadi Sistem Informasi Geografis berbasi WEB (Jhummarwala, dkk 2014) merupakan perangkat lunak yang kaya akan kegunaan untuk berbagai keperluan antara lain untuk 1) perencanaan; 2) analisis: 3) dan pengambilan keputusan/ kebijakan mengenai suatu daerah. Sistem Informasi Geografis di era industri sekarang ini dapat membantu setiap aktivitas di lingkungan pemerintahan. Hal tersebut tentu dapat berjalan sukses apabila diimplementasikan dengan baik dan optimal. Dalam melakukan berbagai keperluan analisis sistem informasi geografis dapat menggunakan beberapa pilihan perangkat lunak salah satunya adalah ArcGIS yang dikembangkan oleh perusahaan Esri (Environmental Systems Research Institue). ArcGIS Online telah menjadi acuan dalam perkembangan teknologi GIS sejak tahun 1999 serta menjadi salah satu platform GIS terdepan di dunia (Esrilndonesia, 2015).

Adapun produk yang dikembangkan oleh ESRI tersebut diantaranya adalah ArcGIS Online. Seperti yang sudah dijelaskan sebelumnya pada bagian awal bahwa ArcGIS Online memiliki berbagai fitur dan dapat digunakan untuk berbagai keperluan terutama di lingkungan pemerintahan. Dengan berkembangnya teknologi GIS dalam hal ini 
adalah perangkat lunak ArcGIS tentu perlu juga didukung oleh sumber daya manusia yang mahir dalam mengoperasikan perangkat lunak tersebut. Pada kenyataanya tidak semua di instansi pemerintahan memiliki ahli GIS sehingga hal tersebut menjadi kendala bagi kantor pemerintahan dalam melakukan pengolahan atau analisis spasial menggunakan perangkat lunak ArcGIS.

ArcGIS Online merupakan platform kolaboratif berbasis cloud yang memungkinkan anggota organisasi untuk menggunakan, membuat, dan berbagi peta, pemandangan, aplikasi, dan data, serta mengakses peta dasar resmi dan aplikasi yang siap digunakan. Selain itu pengguna ArcGIS Online juga akan mendapatkan akses pada cloud aman Esri, dimana merupakan tempat untuk mengelola, membuat, dan menyimpan data sebagai lapisan web yang dipublikasikan (ESRI, 2012). Pada dasarnya ArcGIS Online merupakan bagian integral dari sistem ArcGIS sehingga, pengguna dapat menggunakannya untuk memperluas kemampuan ArcGIS untuk Desktop, ArcGIS untuk Server, API Web ArcGIS, dan SDK Waktu Proses ArcGIS.

Dalam pelaksanaan proses pembelajaran/ pelatihan metode yang diterapkan adalah menggunakan metode pembelajaran jarak jauh. Meskipun ada beberapa preblematika mengenai pembelajaran daring seperti lemahnya penguasan $\mathrm{TI}$ baik bagi pemberi materi atau penerima materi serta keterbatasan fasilitas pendukung dan akses jaringan (Asmuni, 2020). Kemudian terlepas dari problematika yang ada, alasan daripada memilih metode tersebut adalah tidak lain karena kondisi yang tidak memungkinkan untuk dilaksanakannya secara tatap muka. Menurut Fahmi Hanif (2020) dijelaskan bahwa dampak dari covid-19 memberikan nuansa baru terhadap proses pembelajaran disatuan pendidikan. Proses pembelajaran yang berlangsung saat ini sebagian besar menggunakan metode blended learning dimana metode tersebut mengkombinasikan antara metode synchronous dan asynchronous. Metode pembelajaran synchronous mengacu pada pembelajaran/ pengajaran yang terjadi secara bersamaan melalui moda elektronik (Perveen, 2016) dengan memanfaatkan ruang obrolan suara atau teks yang sinkron sehingga memberikan kesempatan interaksi antara pemateri dan peserta. Kemudian metode asynchronous merupakan metode pembelajaran jarak jauh dengan memberikan modul ataupun bahan ajar sebagai penunjang dan penugasan yang dilakukan secara tidak langsung. Metode asynchronous telah menjadi bentuk pengajaran daring yang paling umum karena penerapannya yang fleksibel (Hrastinski, 2008). Pada kesempatan kali ini metode yang diterapkan untuk penyampaian materi lebih pada metode synchronous dimana pemberi materi dan penerima materi melakukan komunikasi dalam bentuk pertemuan virtual menggunakan platform rapat virtual yaitu platform zoom meeting. Pada penggunaan platform tersebut diharapkan seluruh materi yang disampaikan dapat diterima dengan baik oleh para peserta sehingga peserta dapat mendapatkan pengetahuan terbaru mengenai materi yang disampaikan.

Sistem Informasi Berbasis Spasial popular digunakan dan terus berkembang seiring berjalannya waktu khususnya bagi mereka yang berkecimpung di dunia pemetaan. Meskipun teknologi tersebut terbilang popular namun pada kenyataannya masih banyak masyarakat umum yang belum memahami mengenai teknologi tersebut. Berdasarkan informasi yang diperoleh bahwa permasalahan tersebut justru hampir sebagian besar berada di lingkungan Instansi Pemerintahan baik Pusat maupun Daerah. Beberapa Instansi sebagian besar kekurangan sumber daya khususnya mereka yang ahli dibidang geospasial. Keterbatasan pengetahuan tersebut tentu mengakibatkan ketertinggalan bagi mereka mengenai pengetahuan tentang teknologi geospasial. Jika hal tersebut terus dibiarkan maka yang terjadi adalah tidak adanya peningkatan dari segi keahlian dalam melakukan pemetaan secara digital. Selain itu dampak jangka panjang dari permasalahan tersebut adalah Instansi akan selalu menerapkan metode-metode konvensional yang kemudian segala bentuk pekerjaan pemetaan tidak akan berjalan secara efektif dan efisien. Hal tersebut tentu menjadi tantangan bagi mereka untuk berlomba-lomba dalam meningkatkan kompetensi dibidang teknologi geospasial seperti mengikuti kegiatan workshop ataupun kegiatan-kegiatan lainnya yang dapat meningkatkan kemampuan dibidang teknologi geospasial. Berangkat dari permasalahan tersebut maka dengan demikian untuk meningkatkan softskill tersebut maka pendekatan dilakukan dengan cara memberikan suatu pelatihan. Pelaksanaan pelatihan mengenai geospasial dilakukan dengan harapan seluruh OPD baik di tingkat pusat ataupun daerah dapat memahami apa itu teknologi spasial beserta perangkat lunak apa saja yang digunakan dalam melakukan pembuatan peta berbasis teknologi geospasial.

\section{METODE}

Metode yang digunakan pada pengabdian masyarakat ini berupa metode 
pelatihan yang dilakukan secara jarak jauh. Informasi mengenai jadwal pelatihan dibuat menggunakan pamflet dan disebarkan melalui media sosial seperti Instagram dan Whatsapp. Para peserta kemudian mendaftarkan diri pada link yang tertera pada pamflet dan mendapatkan pemberitahuan pada masingmasing email yang didaftarkan pada link. Pada pelatihan ini peserta hanya diperuntukkan untuk mahasiswa dan para OPD (Organisasi Perangkat Daerah) yang mendalami atau berkecimpung di bidang pemetaan. Para peserta mengikuti pelatihan/ pembelajaran via zoom dan dipandu oleh instruktur atau trainer. Sebelum pelatihan dimulai, Trainer menjelaskan tata tertib mengenai pelatihan sehingga diharapkan pelatihan dapat berjalan dengan baik. Trainer memandu peserta tahapan demi tahapan dari awal mulai hingga selesei. Trainer juga memberikan kesempatan kepada para peserta untuk bertanya jika ada salah satu peserta yang kurang memahami apa yg sudah dijelaskan oleh trainer. Ketika pelatihan sedang berlangsung, trainer juga memberikan absensi online kepada para peserta melalui kolom chat aplikasi zoom. Para peserta yang sudah mengisi absensi akan memperoleh sertifikat sebagai tanda telah mengikuti pelatihan tersebut.

\section{HASIL DAN PEMBAHASAN}

Sistem Informasi Geografis pada prinsipnya merupakan sistem informasi berbasis lokasi (geotagging). Adapun menurut jurnal (Defitria dkk, 2018.) Geotagging adalah sebuah proses penambahan informasi posisi data pada GPS berupa informasi latitude dan longitude dalam sebuah foto digital. Penerapan dari konsep SIG tentu didukung dengan beberapa data yang selanjutnya disebut dengan data spasial. Data spasial yang dimaksud kemudian dapat digunakan untuk analisis lebih lanjut seperti pemodelan data spasial, pemetaan sebaran suatu lokasi, serta analisis lainnya yang berhubungan dengan pengambilan keputusan. Teknologi yang menggunakan sistem informasi geografis begitu popular digunakan dalam bidang pemetaan khususnya dalam memvisualisasikannya secara digital.Pada pelatihan yang berjudul "solusi pemulihan ekonomi berbasis teknologi geospasial untuk pemerintah daerah" didasari pada meningkatnya permintaan pasar baik untuk kebutuhan komersial ataupun non komersial oleh karena itu tema yang diangkat pada pelatihan ini dapat bermanfaat bagi para peserta yang nantinya dapat digunakan untuk keperluan pemetaan khususnya di instansiinstansi pusat ataupun daerah. Pelatihan ini diikuti oleh 41 Peserta dimana sebagian besar peserta diikuti oleh berbagai OPD (Organisasi Perangkat Daerah) di Wilayah Sumatera Selatan. Adapun OPD Tersebut antara lain berasal dari ; 1) Dinas Perdagangan dan UKM Kabupaten Banyuasin, Bappeda Kabupaten Ogan Ilir, Badan Perencanaan Daerah Kabupaten Ogan Ilir, Bappeda Provinsi Sumatera Selatan, Dinas Ketahanan Pangan Kabupaten Banyuasin, Dinas Komunikasi dan Informatika Kabupaten Banyuasin, Dinas Permukiman Kabupaten Banyuasin, Dinas Sosial Kabupaten Banyuasin, Dinas Kesehatan Banyuasin, Dinas PUPR Kabupaten Banyuasin, Dinas Pendidikan dan Kebudayaan Kabupaten Banyuasin, Bappeda dan Litbang Kabupaten OKU Timur, dan Dinas Pertanian Kabupaten Banyuasin. Para peserta antusias ketika melakukan pelatihan hal tersebut ditandai dengan banyaknya peserta yang mengajukan pertanyaan selama proses pelatihan berlangsung. Ada beberapa tahapan yang dilakukan pada pelatihan tersebut. Adapun tahapan-tahapan yang dilakukan antara lain:

1. Melakukan pembuatan akun pada perangkat lunak ArcGIS Online dan melakukan penambahan data

2. Membuat form survey pendataan usaha kecil menggunakan ArcGIS Survey123

3. Membuat Web Map (Peta Online) di ArcGIS Online

Tahapan-tahapan tersebut kemudian akan dijelaskan pada sub sub bab berikutnya.

\section{Pembuatan Akun dan Penambahan Data}

Pada tahapan ini peserta dipandu untuk melakukan pembuatan akun pada perangkat lunak yang digunakan. Para peserta dapat melakukan sign in dengan mengetikkan username dan password yang sebelumnya sudah diberikan oleh trainer. Setelah akun berhasil dibuat kemudian selanjutnya dilakukan pembuatan folder pada tab my content pada tampilan halaman depan web. Pada tampilan pembuatan folder, dilakukan pengisian nama folder yang sebelumnya sudah ditentukan. Ketika folder berhasil dibuat kemudian dilakukan penambahan item pada folder tersebut dan menambahkan item data yang bersumber dari layanan web (web service) Setelah klik from URL kemudian akan diarahkan untuk menambahkan data yang bersumber dari web Kemudian setelah Data tersebut berhasil dimasukkan, maka pada tab konten di folder yang telah ditentukan akan memiliki item berupa fitur layer. Berikut ditampilkan halaman depan dari perangkat lunak ArcGIS Online. 


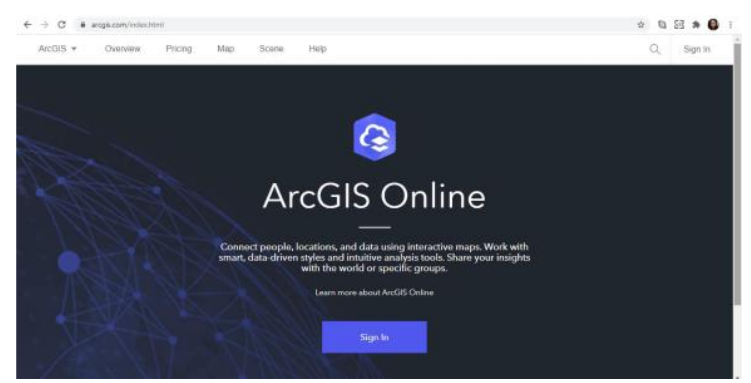

Gambar 1 Tampilan Pembuatan Akun

\section{Pembuatan Form Survei123}

Setelah proses sebelumnya dilakukan maka langkah selanjutnya adalah melakukan pembuatan form survey pada laman web survey123.arcgis.com. Pada Bagian ini peserta melakukan login menggunakan username dan password yang sebelumnya sudah ditentukan. Setelah berhasil masuk para peserta melakukan pembuatan formulir survey baru dengan melakukan beberapa pengisian seperti pengisian name, tag, dan summary. Kemudian setelah pengisian tersebut dilakukan selanjutnya adalah melakukan pembuatan desain pada formulir survey tersebut. Adapun hasil dari pengisian pada desain formulir survei adalah sebagai berikut.

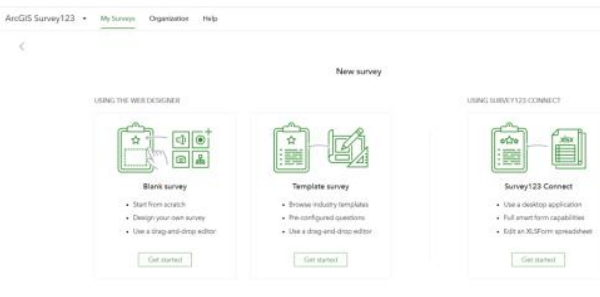

Gambar 2 Tampilan Pembuatan Form Survey

\section{Pembuatan Peta Online}

Pada bagian ini merupakan hasil dari pembuatan peta online yang dilakukan oleh para peserta pelatihan. Para peserta dituntut untuk bisa melakukan pembuatan peta online seperti yang sudah disampaikan oleh trainer diwaktu pelatihan. Adapun hasil yang diperoleh para peserta pada bagian ini ditampilkan pada gambar berikut.

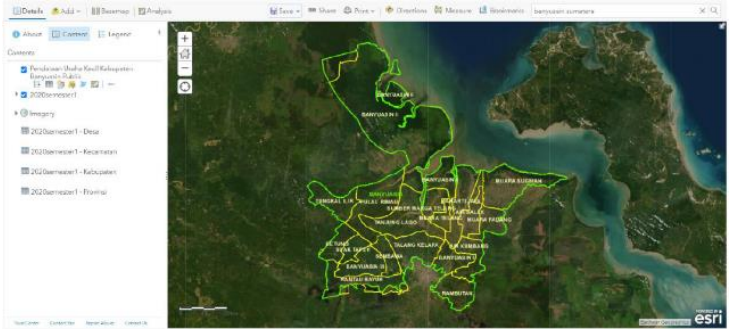

Gambar 3 Tampilan Pembuatan Peta Online

\section{SIMPULAN DAN SARAN}

Para peserta pelatihan khususnya para OPD (Organisasi Perangkat Daerah) dinilai sangat antusias dalam mengikuti pelatihan tersebut. Hal tersebut bisa dilihat selama proses pelatihan berlangsung dimana pada saat sesi tanya jawab sebagian besar dari para OPD mengajukan pertanyaan-pertanyaan pada trainer pelatihan. Selain itu, para peserta yang awalnya banyak yang tidak memahami bagaimana cara melakukan pembuatan peta online, ketika selesai melaksanakan pelatihan para peserta banyak memahami hal-hal tersebut. Hal tersebut tentunya memiliki dampak baik terutama pada peningkatan pengetahuan dibidang pemetaan. Selain itu cara-cara pembuatan peta online mengalami peningkatan yang signifikan dibandingkan dengan sebelum dan sesudah melaksanakan pelatihan.

Pendekatan pelatihan dengan metode jarak jauh tentu menjadi alternatif dari metode tatap muka. Namun, bagaimanapun juga pendekatan dengan metode jarak jauh memiliki berbagai kendala salah satunya adalah jaringan yang tidak stabil. Oleh karena itu, untuk pelatihan selanjutnya diharapkan dapat dilaksanakan secara tatap muka agar proses pelatihan dapat dilakukan secara interaktif dan lebih efektf. Selain itu untuk rekomendasi selanjutnya selain memberikan pengetahuan cara melakukan pembuatan peta online menggunakan web ArcGIS Online, agar kedepannya dapat dilaksanakan pemahaman mengenai pembuatan peta online menggunakan perangkat lunak lainnya sehingga akan memberikan wawasan yang semakin luas pada pemahaman pemetaan.

\section{DAFTAR RUJUKAN}

Asmuni. (2020). Problematika Pembelajaran Daring Di Masa Pandemi Covid-19 Dan Solusi Pemecahannya. Vol. 7, no. 4, pp. 281-88.

Budiyanto, Eko. (2010). Sistem Informasi Geografis Dengan ArcView GIS. CV. Andi Offset.

Defitria, Ulfani, et al. (2018). Pembangunan Aplikasi Social Geotagging Destinasi Wisata Berbasis Android. Vol. 2, no. 12, pp. 6610-17.

ESRI. (2012). Quick Start Guide To ArcGIS Online.Pdf.

Fahmi Hanif, Muhammad. (2020). "Komunikasi Synchronous Dan Asynchronous Dalam E-Learning Pada Masa Pandemic Covid19." Jurnal Nomosleca, vol. 6.

Hrastinski, Stefan. (2008). Asynchronous and Synchronous E-Learning. no. 4, pp. 51-55.

Indonesia, Esri. (2015). Platform ArcGIS 
Developer.

Jhummarwala, Abdul. (2014). Parallel and Distributed GIS for Processing Geo-Data : An Overview. Vol. 106, no. 16, pp. 9-16.

Perveen, Ayesha. Synchronous and Asynchronous E-Language Learning: A Case Study of Virtual University of Pakistan. Vol. 8, no. 1, 2016, pp. 21-39.

Prahasta, Eddy. (2009). Informasi Geografis Konsep-Konsep Dasar. CV. Informatika. 